\title{
Clinical outcomes of non-diabetic COVID-19 patients with different blood glucose levels: a nationwide Turkish study (TurCoGlycemia)
}

\author{
Cem Haymana $\mathbb{B}^{1}$ et al.
}

Received: 5 May 2021 / Accepted: 3 June 2021 / Published online: 22 June 2021

(c) The Author(s), under exclusive licence to Springer Science+Business Media, LLC, part of Springer Nature 2021

\begin{abstract}
Purpose New coronavirus disease 2019 (COVID-19) has a worse prognosis in patients with diabetes. However, there are insufficient data about the effect of hyperglycemia on COVID-19 prognosis in non-diabetic patients. This study aimed to investigate the relationship between random blood glucose levels measured at the time of diagnosis and prognosis of COVID-19 disease in non-diabetic patients.

Methods A nationwide retrospective cohort of non-diabetic patients with confirmed COVID-19 infection from 11 March to 30 May 2020 in the Turkish Ministry of Health database was investigated. The patients were stratified into three groups according to blood glucose levels which were $<100 \mathrm{mg} / \mathrm{dL}$ in group-1, in the range of 100-139 $\mathrm{mg} / \mathrm{dl}$ in group-2, and the range of 140-199 mg/dl in group-3. Clinical characteristics and outcomes were compared among the groups. The primary outcome was mortality.

Results A total of 12,817 non-diabetic patients (median age [IQR]: 44 [25] years, females: 50.9\%) were included. Patients in group-2 (5\%) and group-3 (14\%) had higher mortality rates than patients in group-1 (2.1\%). The rates of hospitalization, hospital stays longer than 8 days, intensive care unit (ICU) admission, ICU stay more than 6 days, and mechanical ventilation were also significantly higher in group-3 patients. Likewise, glucose levels in the range of $140-199 \mathrm{mg} / \mathrm{dL}$ were an independent associate of mortality and composite of ICU admission and/or mechanical ventilation.

Conclusion Hyperglycemia at the time of COVID-19 diagnosis is associated with poor prognosis in non-diabetic patients. Clinicians should be more careful in the treatment of non-diabetic COVID-19 patients with hyperglycemia.
\end{abstract}

Keywords COVID-19 $\cdot \mathrm{SARS}-\mathrm{CoV}-2 \cdot$ Hyperglycemia $\cdot$ Hospitalization $\cdot$ ICU admission $\cdot$ Mechanical ventilation Mortality

\section{Introduction}

New coronavirus disease 2019 (COVID-19) caused by severe acute respiratory syndrome coronavirus 2 (SARS-CoV-2) has been one of the most important epidemics of the century threatening human health worldwide. Due to the COVID-19, more than 130 million patients have been infected, and more than 2.8 million deaths have occurred around the world [1,2].

Mortality and morbidity rates of COVID-19 disease increase significantly in certain population groups such as males, older adults, or patients with comorbidities. Type 2 diabetes mellitus (T2DM) is one of the most frequent

Cem Haymana

cemhaymana@hotmail.com

Extended author information available on the last page of the article comorbidities in COVID-19 patients with considerably increased mortality and morbidity rates [3,4]. Moreover, recent data indicate that new-onset hyperglycemia is common among hospitalized COVID-19 patients with no history of diabetes in the past. Besides, hyperglycemia on hospital admission is a significant prognostic factor for COVID-19 patients without diabetes mellitus [5-8]. Studies from the United States, Italy, Spain, and China have consistently shown an increased risk of mortality, intensive care unit (ICU) admission, and a need for mechanical ventilation in patients with on admission hyperglycemia but no previous diagnosis of diabetes mellitus [5-9].

On the other hand, not all COVID-19 patients require hospitalization at the time of diagnosis. While the studies that have shown the impact of hyperglycemia on COVID-19 outcomes were performed exclusively in hospitalized patients, very little information has been obtained from the less severe COVID-19 population who comprise a great proportion of the confirmed 
Fig. 1 Study inclusion flow chart

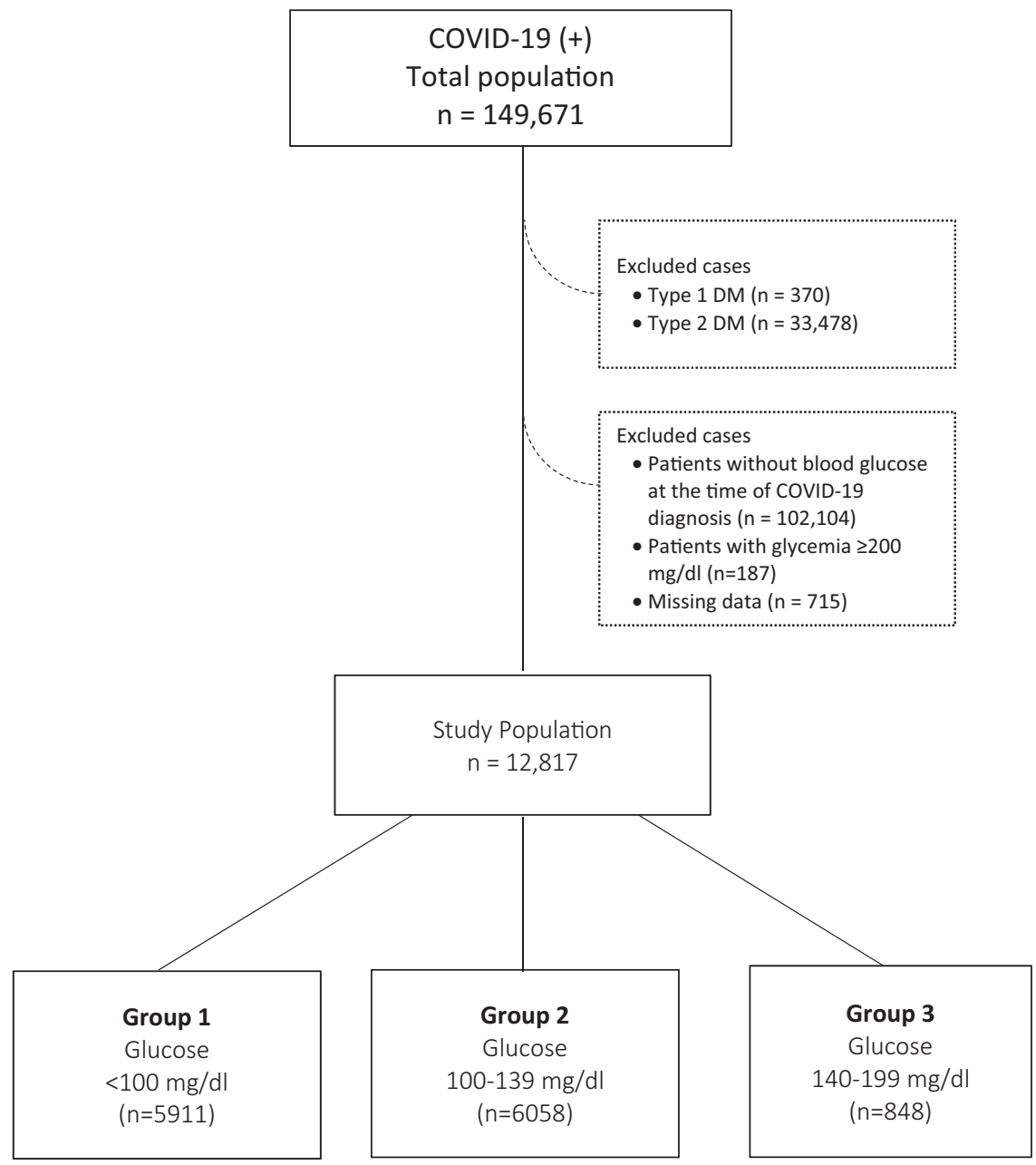

cases. Moreover, criteria to exclude patients with diabetes and define hyperglycemia were not consistent across different studies mentioned above. In this study, we aimed to investigate the association of blood glucose levels by the time of COVID-19 diagnosis and clinical outcomes including hospitalization, mortality, and ICU admission and/or a need for mechanical ventilation in COVID-19 patients without diabetes mellitus.

\section{Materials and methods}

\section{Study design and participants}

This nationwide study was conducted using the COVID-19 registry of the Turkish Ministry of Health National Electronic Database. To promote data sharing with the scientific society, demographic, clinical, and outcome data of all symptomatic confirmed cases of COVID-19 infection were made available to the author group under the supervision of the Ministry of Health, and several publications have been made so far [10, 11]. The study population included 149,671 adult patients with confirmed COVID-19 (PCR positive) diagnosis from 11 March through 30 May 2020. Figure 1 illustrates the patient enrollment. Briefly, patients with type 1 diabetes mellitus $(n=370)$, T2DM $(n=33,478)$, or unclassified ( $n=715$, see "Definitions" below), with blood glucose level above $200 \mathrm{mg} / \mathrm{dl}(n=187)$ and no glucose measurement $(n=102,104)$ at the time of COVID-19 diagnosis were excluded from the analysis. The final study population comprised 12,817 confirmed COVID-19 patients without previously known diabetes. The patients were stratified into three groups according to glucose level which was $<100 \mathrm{mg} / \mathrm{dL}$ in group-1, in the range of $100-139 \mathrm{mg} / \mathrm{dl}$ in group-2, and in the range of $140-199 \mathrm{mg} / \mathrm{dl}$ in group-3. The design and procedures in the study are in accordance with the Declaration of Helsinki and the study protocol was approved by the COVID-19 Investigation Review Board under the General Directorate of Health Services Bioethics Committee (IRB no: 95741342-020:186404/28.10.2020).

\section{Data collection}

Sociodemographic characteristics (gender, age, body mass index (BMI), smoking, and education), comorbid diseases, 
and information on medications were recorded. Blood glucose, low-density lipoprotein cholesterol (LDL-cholesterol), high-density lipoprotein cholesterol (HDL-cholesterol), total cholesterol, and triglycerides, creatinine, alanine and aspartate aminotransferases (ALT and AST), C-reactive protein (CRP), lymphocyte count, procalcitonin, lactate dehydrogenase (LDH), ferritin, fibrinogen, and D-dimer were obtained from the national database. Blood glucose levels measured within $24 \mathrm{~h}$ of COVID-19 diagnosis were recorded regardless of fasting state. Chest computerized tomography (CT) results were available in the national database and recorded as positive (bilateral distribution of patchy shadows or ground-glass opacity) or negative for COVID-19.

\section{Definitions}

Smoking was defined as currently smoking at the time of the COVID-19 diagnosis. Hypertension, dyslipidemia, chronic obstructive pulmonary disease (COPD), asthma, heart failure, cardiovascular disease (CVD) (combined coronary artery, peripheral artery, and cerebrovascular diseases) were identified using the International Classification of Diseases System-10 (ICD-10) codes. BMI was calculated as the ratio of weight to the square of heights $\left(\mathrm{kg} / \mathrm{m}^{2}\right)$. Obesity was defined as $\mathrm{BMI} \geq 30 \mathrm{~kg} / \mathrm{m}^{2}$. Chronic kidney disease was defined as a decreased estimated glomerular filtration rate (eGFR: $<60 \mathrm{~mL} / \mathrm{min} / 1.73 \mathrm{~m}^{2}$ ) based on the CKD-EPI equation [12]. Renin-angiotensin system (RAS) blocker use was defined as receiving any angiotensinconverting enzyme inhibitors or angiotensin receptor blockers with/without their combination forms. Patients who did not have an ICD-10 code for type 1 diabetes or T2DM in twelve months past or patients who had an HbA1c value below $6.5 \%$ along with the absence of any antihyperglycemic medication were defined as non-diabetic. Patients with missing data were excluded.

\section{Study outcomes}

The primary outcome was mortality. The secondary outcomes were the rates of hospitalization and ICU admission and/or mechanical ventilation.

\section{Statistical analyses}

Numerical data were expressed as median (interquartile rangeIQR) and categorical variables as counts $(n)$ and percentage (\%). Normality of distribution was assessed using the Kolmogorov-Smirnov test. Differences between groups were assessed using the Chi-square test for categorical variables and the student's $t$-test or the Mann-Whitney $U$ test, as appropriate. Univariate analyses were performed to evaluate the potential variables associated with mortality, hospitalization, and ICU admission, and/or mechanical ventilation and presented with an odds ratio (OR) and $95 \%$ confidence intervals (CI). Multivariable logistic regression analysis was used to study the independently associated risk factors of the three outcomes. Variables with significant univariate association with the outcomes and variables which could be potential predictors despite the lack of significant univariate association were included in a multivariate model. Hosmer-Lemeshow and the likelihood ratio tests were used to assess final model fitting. Statistical significance was defined as a two-sided $p$ value of $\leq 0.05$. All data were analyzed using Statistical Package for the Social Sciences (SPSS) for Windows 25.0 (SPSS Inc. 111 Chicago, IL).

\section{Results}

\section{Basic characteristics}

The median age of the study population $(n=12,817)$ was 44 (25) years, and $50.9 \%$ was female. The demographic and clinical parameters of the three groups are displayed in Table 1. The percentage (number) of patients in group-1, 2, and 3 were $46.1 \%(n=5911), 47.3 \%(n=6058)$, and 6.6\% $(n=848)$, respectively. Median age, male sex, and mean BMI showed increases from group 1 to group 3. The current smoking rates in the groups were $21.2,19.1$, and $22.4 \%$, respectively.

As shown in Table 1, most laboratory test results showed a significantly worse direction from group-1 to group-3. Notably, D-dimer, CRP, LDH, ferritin, and lymphopenia that were more commonly referred to COVID-19 severity, increased gradually across the groups. Only three laboratory variables, total cholesterol, LDL-cholesterol, and fibrinogen, were not different from normal glucose to high glucose group. Lung involvement on CT increased considerably from group-1 to group-3.

The prevalences of hypertension, dyslipidemia, obesity, asthma/COPD, heart failure, CVD, chronic kidney disease, and cancer were significantly different among the three groups, with more than double the increase in the frequencies of CVD, heart failure, chronic kidney disease, and medications in group 3 (Table 1). Similarly, the use of RAS blockers, statins, and acetylsalicylic acid (ASA) was more common in group-3.

\section{Outcome analysis}

There were significant differences in the primary and secondary outcomes across the groups. Mortality rate was found to be $14 \%$ in group-3, which was significantly higher than the mortality rate of $5 \%$ and $2.1 \%$ in group- 2 and group-1, respectively. Mortality was also significantly higher in group-2 compared to group-1. Similar differences 
Table 1 Clinical and laboratory parameters of patients according to the different blood glucose levels

\begin{tabular}{|c|c|c|c|c|c|}
\hline & $\begin{array}{l}\text { Group-1 Glucose } \\
<100 \mathrm{mg} / \mathrm{dl} \\
(n=5911,46.1 \%)\end{array}$ & $\begin{array}{l}\text { Group-2 Glucose } \\
100-139 \mathrm{mg} / \mathrm{dl} \\
(n=6058,47.3 \%)\end{array}$ & $\begin{array}{l}\text { Group-3 Glucose } \\
140-199 \mathrm{mg} / \mathrm{dl} \\
(n=848,6.6 \%)\end{array}$ & $\begin{array}{l}\text { Total available } \\
\text { data } \\
(n=12,817)\end{array}$ & $p$ \\
\hline Age, years, median (IQR) & $35(19)^{* * * *}$ & $45(22)^{* * *}$ & $55(20)$ & 12817 & $<0.001$ \\
\hline Gender, female, $n(\%)$ & $3137(53.1)^{* * * *}$ & $3009(49.7)^{* * *}$ & $383(45.2)$ & 12817 & $<0.001$ \\
\hline Smoking (current smoker - $n, \%$ ) & $952(21.2)$ & $832(19.1)$ & $125(22.4)$ & 9417 & 0.022 \\
\hline BMI, kg/m², median (IQR) & $25.5(6.1)$ & $27.2(6.1)$ & $28.4(5.6)$ & 1483 & $<0.001$ \\
\hline \multicolumn{6}{|l|}{ Comorbid conditions } \\
\hline Hypertension, $n(\%)$ & $1950(33.0)$ & $2739(45.2)$ & $503(59.3)$ & 12817 & $<0.001$ \\
\hline Dyslipidemia, $n(\%)$ & $601(10.2)$ & $849(14.0)$ & $178(21.0)$ & 12817 & $<0.001$ \\
\hline Obesity, $n(\%)$ & $121(17.5)$ & $187(27.0)$ & $34(34.3)$ & 1482 & $<0.001$ \\
\hline Asthma/COPD, $n(\%)$ & $1233(20.9)$ & $1561(25.8)$ & $271(32.0)$ & 12817 & $<0.001$ \\
\hline Heart failure, $n(\%)$ & $179(3.0)$ & $266(4.4)$ & $60(7.1)$ & 12817 & $<0.001$ \\
\hline CVD, $n(\%)$ & 868 (14.7) & 1309 (21.6) & 293 (34.6) & 12817 & $<0.001$ \\
\hline Chronic kidney disease, $n(\%)$ & $306(5.6)$ & $551(9.7)$ & $125(15.7)$ & 11947 & $<0.001$ \\
\hline Cancer, $n(\%)$ & $309(5.2)$ & $384(6.3)$ & $88(10.4)$ & 12817 & $<0.001$ \\
\hline \multicolumn{6}{|l|}{ Laboratory values } \\
\hline $\begin{array}{l}\text { Chest CT on admission } \\
\text { consistent with COVID-19, } \\
n(\%)\end{array}$ & $1615(29.2)^{* * * *}$ & $2126(36.5)^{* * *}$ & $354(43.4)$ & 12161 & $<0.001$ \\
\hline Glucose, mg/dL, median (IQR) & $90(10)$ & $110(16)$ & $152(32)$ & 12769 & $<0.001$ \\
\hline $\begin{array}{l}\text { Total cholesterol, mg/dL, } \\
\text { median (IQR) }\end{array}$ & $178(58.7)$ & $179.5(66.1)$ & $196(68)$ & 1141 & 0.151 \\
\hline $\begin{array}{l}\text { Triglycerides, mg/dL, } \\
\text { median (IQR) }\end{array}$ & $105(90.5)$ & $126(98.5)$ & $136(103)$ & 1556 & 0.003 \\
\hline $\begin{array}{l}\text { HDL-cholesterol, mg/dL, } \\
\text { median (IQR) }\end{array}$ & $48.7(21.3)$ & $45(18)$ & $47(16.4)$ & 1205 & 0.026 \\
\hline $\begin{array}{l}\text { LDL-cholesterol, mg/dL, } \\
\text { median (IQR) }\end{array}$ & $106.5(46.8)$ & $111.5(58)$ & $118(53.9)$ & 1090 & 0.235 \\
\hline $\begin{array}{l}\text { eGFR, } \mathrm{ml} / \mathrm{min} / 1.73 \mathrm{~m}^{2} \text {, } \\
\text { median (IQR) }\end{array}$ & $105.3(53.1)$ & $99.2(48.6)$ & $91.1(54.1)$ & 8563 & $<0.001$ \\
\hline AST > ULN, $n(\%)$ & $311(12.8)$ & $526(18.4)$ & $104(24.9)$ & 5714 & $<0.001$ \\
\hline ALT $>$ ULN, $n(\%)$ & $392(16.2)$ & $545(19.2)$ & $101(24.3)$ & 5684 & $<0.001$ \\
\hline D-dimer $>\mathrm{ULN}, n(\%)$ & $374(33.2)$ & $429(38.4)$ & $85(51.5)$ & 2406 & $<0.001$ \\
\hline $\mathrm{CRP},>\mathrm{ULN}, n(\%)$ & $1760(49.3)$ & $2405(61.8)$ & $390(68.3)$ & 8031 & $<0.001$ \\
\hline Procalcitonin, >ULN, $n(\%)$ & $35(6.3)$ & $51(9.8)$ & $21(22.6)$ & 1168 & $<0.001$ \\
\hline $\begin{array}{l}\text { Lactate dehydrogenase, }>\text { ULN, } \\
n(\%)\end{array}$ & $620(26.1)$ & $976(38.2)$ & $168(46.4)$ & 5286 & $<0.001$ \\
\hline Ferritin, $>100 \mathrm{ng} / \mathrm{mL}, n(\%)$ & $716(42.8)$ & $867(52.4)$ & $159(67.4)$ & 3565 & $<0.001$ \\
\hline Fibrinogen, >ULN $n(\%)$ & $176(64.7)$ & $199(69.3)$ & $35(61.4)$ & 616 & 0.351 \\
\hline $\begin{array}{l}\text { Lymphopenia, Lym \# <1000, } \\
n(\%)\end{array}$ & $698(17.1)$ & $961(22.7)$ & $164(29.1)$ & 8869 & $<0.001$ \\
\hline \multicolumn{6}{|l|}{ Treatments } \\
\hline RAS blocker, $n(\%)$ & $960(16.2)$ & $1601(26.4)$ & $330(38.9)$ & 12817 & $<0.001$ \\
\hline Statin, $n(\%)$ & $236(4.0)$ & $378(6.2)$ & $108(12.7)$ & 12817 & $<0.001$ \\
\hline Acetylsalicylic acid, $n(\%)$ & $701(11.9)$ & $1011(16.7)$ & 209 (24.6) & 12817 & $<0.001$ \\
\hline
\end{tabular}

$I Q R$ interquartile range, $B M I$ body mass index, $C T$ computerized tomography, $H D L$-cholesterol high-density lipoprotein cholesterol, $L D L$ cholesterol low-density lipoprotein cholesterol, eGFR estimated glomerular filtration rate, ULN upper limit of normal, AST aspartate amino transferase, $A L T$ alanine amino transferase, $C R P$ C-reactive protein, Lym \# lymphocyte count, COPD chronic obstructive pulmonary disease, $C V D$ cardiovascular disease, $R A S$ renin-angiotensin aldosterone system

Post-hoc tests: $* p<0.05$ group-1 vs. group-2, $* * p<0.05$ group-1 vs. group-3, $* * * p<0.05$ group-2 vs. group-3 


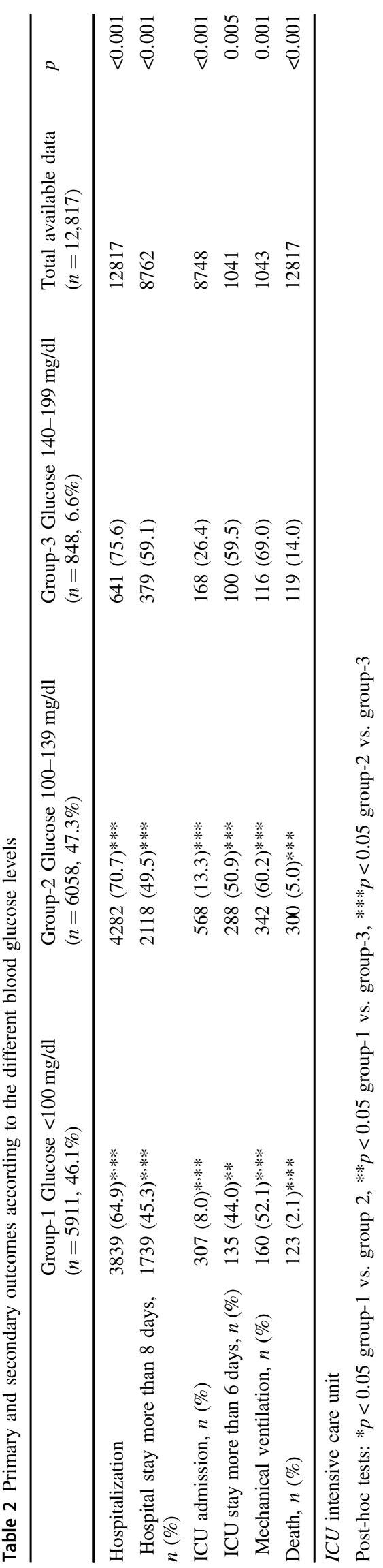

were also found in the rate of hospitalization, hospital stays longer than the median duration (8 days), ICU admission, ICU stay longer than the median duration (6 days), and mechanical ventilation (Table 2).

\section{Independent associations of mortality and secondary outcomes}

Multivariate analyses indicated that age (OR, 95\% CI: 1.02 , 1.01-1.02), lung involvement (OR, 95\% CI: 3.12, 2.58-3.77), lymphopenia (OR, 95\% CI: 1.26, 1.03-1.55), chronic kidney disease (OR, 95\% CI: 1.62, 1.12-2.33), cancer (OR, 95\% CI:1.49, 1.02-2.18) and the use of ASA (OR, 95\% CI: 1.68, 1.24-2.27) were associated with the risk of hospitalization (Table 3 ). In addition, age (OR, 95\% CI: 1.07, 1.06-1.09), male gender (OR, 95\% CI: 2.68, 1.73-4.15), lung involvement (OR, 95\% CI: 1.55 , 1.04-2.32), glucose levels in the range of $140-199 \mathrm{mg} / \mathrm{dl}$ (OR, 95\% CI: 2.66, 1.41-5.00), lymphopenia (OR, 95\% CI: 1.1.87, 1.25-2.80), CRP (OR, 95\% CI: 3.11, 1.69-5.73), hypertension (OR, 95\% CI:1.95, 1.00-3.79) and chronic kidney disease (OR, 95\% CI:2.16, 1.40-3.35) associated with mortality (Table 2). Also, age (OR, 95\% CI: 1.04, 1.03-1.05), male gender (OR, 95\% CI: 1.92, 1.46-2.53), lung involvement (OR, 95\% CI: 1.63, 1.25-2.13), glucose level in the range of 140-199 mg/dl (OR, 95\% CI: 2.26, 1.45-3.52), lymphopenia (OR, 95\% CI:2.03, 1.54-2.66), CRP (OR, 95\% CI: 2.31, 1.67-3.20) and heart failure (OR, 95\% CI: 1.94, 1.26-2.98) were significantly associated with the composite of ICU admission and/or mechanical ventilation (Table 2).

The Kaplan-Meier graph of 30-day mortality curves in the total sample is given in Fig. 2. The rate of mortality in group 3 patients was significantly higher (Log-Rank test: $p<0.001)$ than in other groups.

\section{Discussion}

The present study showed that non-diabetic COVID-19 patients who had increased glucose levels at the time of diagnosis were at increased risk of mortality, longer hospitalization, ICU admission, and a need for mechanical ventilation than patients with lower blood glucose. On the other hand, glucose levels at the time of diagnosis was not independently associated with the occurrence of hospitalization. Additional variables such as age, male gender, lung involvement, lymphopenia, CRP, hypertension, and chronic kidney disease were associated with reduced survival in non-diabetic patients with COVID-19 disease.

Many studies reported that diabetes mellitus, especially T2DM, is one of the most frequent comorbidities in COVID-19 patients $[10,11,13-15]$. The findings also 
Table 3 Adjusted ORs and 95\% CIs for different levels of blood glucose from multivariate logistic regression (dependent variables: hospitalization, ICU admission and/or mechanical ventilation, and mortality)

\begin{tabular}{|c|c|c|c|c|c|c|}
\hline & \multicolumn{2}{|l|}{ Hospitalization } & \multicolumn{2}{|c|}{$\begin{array}{l}\text { ICU Admission and/or } \\
\text { Mechanical Ventilation }\end{array}$} & \multicolumn{2}{|l|}{ Mortality } \\
\hline & OR $(95 \% \mathrm{CI})$ & $p$ & OR $(95 \% \mathrm{CI})$ & $p$ & OR $(95 \% \mathrm{CI})$ & $p$ \\
\hline \multicolumn{7}{|l|}{ Glucose $<100 \mathrm{mg} / \mathrm{dl}$, ref. } \\
\hline Glucose $100-139 \mathrm{mg} / \mathrm{dl}$ & - & - & $1.24(0.93-1.66)$ & 0.145 & $1.44(0.91-2.29)$ & 0.119 \\
\hline Glucose $140-199 \mathrm{mg} / \mathrm{dl}$ & - & - & $2.26(1.45-3.52)$ & $<0.001$ & $2.66(1.41-5.00)$ & 0.002 \\
\hline Age & $1.02(1.01-1.02)$ & $<0.001$ & $1.04(1.03-1.05)$ & $<0.001$ & $1.07(1.06-1.09)$ & $<0.001$ \\
\hline Gender, male ref. & - & - & $1.92(1.46-2.53)$ & $<0.001$ & $2.68(1.73-4.15)$ & $<0.001$ \\
\hline CT findings of COVID-19 & $3.12(2.58-3.77)$ & $<0.001$ & $1.63(1.25-2.13)$ & $<0.001$ & $1.55(1.04-2.32)$ & 0.031 \\
\hline Lymphopenia (Lym\# < 1000/micL) & $1.26(1.03-1.55)$ & 0.027 & $2.03(1.54-2.66)$ & $<0.001$ & $1.87(1.25-2.80)$ & 0.002 \\
\hline $\mathrm{CRP}$ & - & - & $2.31(1.67-3.20)$ & $<0.001$ & $3.11(1.69-5.73)$ & $<0.001$ \\
\hline Hypertension & - & - & - & - & $1.95(1.00-3.79)$ & 0.049 \\
\hline Chronic kidney disease & $1.62(1.12-2.33)$ & 0.010 & - & - & $2.16(1.40-3.35)$ & 0.001 \\
\hline Heart failure & - & - & $1.94(1.26-2.98)$ & 0.003 & - & - \\
\hline Cancer & $1.49(1.02-2.18)$ & 0.037 & - & - & - & - \\
\hline Acetylsalicylic acid & $1.68(1.24-2.27)$ & 0.001 & - & - & - & - \\
\hline
\end{tabular}

$I C U$ intensive care unit, $O R$ odds ratio, $C I$ confidence intervals, $C T$, computerized tomography, $C O V I D-19$ new coronavirus-19, $C R P$ C-reactive protein

Variables included in the multivariate analyses: Glucose levels $<100 \mathrm{mg} / \mathrm{dl}$, Glucose levels between $100-140 \mathrm{mg} / \mathrm{dl}$, Glucose levels between 140-200 mg/dl, Age, Gender, Pulmonary CT findings of COVID-19, Hypertension, Dyslipidemia, Obesity, Asthma/COPD, Heart failure, Cardiovascular disease, Chronic kidney disease, Cancer, Lymphopenia, RAS blockers \pm combinations, Statins, Acetylsalicylic acid (only the significant associates were given in the table)

indicated that hyperglycemic state in patients is very important in the prognosis of COVID-19 disease. Furthermore, some recent studies reported that glycemia levels on hospital admission had a negative impact on the prognosis of COVID-19 disease in non-diabetic patients $[5,6,8,9,16]$. With one of the largest patient groups, the present study showed that hyperglycemia at the time of COVID-19 diagnosis in non-diabetic patients was an independent predictor of mortality and the composite endpoint of ICU admission and/or mechanical ventilation. Especially, glucose levels in the range of 140-199 mg/dl increased the mortality 2.7 fold and the rate of ICU admission and/or mechanical ventilation 2.3 fold, compared to normoglycemia. However, glucose levels in the range of $100-139 \mathrm{mg} / \mathrm{dl}$ had no effect on these outcomes. Our results are consistent with the findings of other studies which showed increased mortality due to hyperglycemia in non-diabetic patients with COVID-19 disease [5-9]. However, each of these studies used different criteria to identify the non-diabetic patients and also used the various thresholds to define hyperglycemia when investigating the effect of glycemia levels. Therefore, there may be some methodological issues, especially in identifying non-diabetic patients and in defining hyperglycemia levels in these studies. For instance, in the study by Coppeli et al., the normoglycemia group was defined as the patients who had glucose levels $<140 \mathrm{mg} / \mathrm{dl}$
[7]. It can be speculated that there may be the probability of having undiagnosed diabetes patients in the normoglycemia group. Also, in another recent study by Carrasco et al., hyperglycemia groups were defined as patients who had glycemia levels in the range of $140-180 \mathrm{mg} / \mathrm{dl}$, and $\geq 180 \mathrm{mg} / \mathrm{dl}$ [9]. Similarly, Bode et al., defined hyperglycemia in patients without diabetes as two or more blood glucose levels $>180 \mathrm{mg} / \mathrm{dL}$ occurred within any 24-hour period with an $\mathrm{HbA} 1 \mathrm{c}<6.5 \%$ or no $\mathrm{HbA} 1 \mathrm{c}$ testing performed during hospitalization [5]. In both studies, hyperglycemia in non-diabetic patients was significantly associated with increased mortality compared to patients with normoglycemia. However, diabetes mellitus diagnosis may be missed in a significant proportion of patients with glycemia levels above $180 \mathrm{mg} / \mathrm{dl}$ in both studies. In the current study, we used the glucose cut-off levels for normoglycemia as $<100 \mathrm{mg} / \mathrm{dl}$ and did not include the glucose values above $200 \mathrm{mg} / \mathrm{dl}$ in order to eliminate false negativity regarding the diagnosis of diabetes. In addition, we excluded patients who use antidiabetic drugs, have $\mathrm{HbA} 1 \mathrm{c} \geq 6.5 \%$, and have a diagnosis of diabetes with an ICD-10 diagnostic code. Therefore, we think that we had a very homogeneous patient population in order to demonstrate the effect of hyperglycemia in non-diabetic patients.

It is not surprising that hyperglycemia was associated with mortality in non-diabetic patients with COVID-19 
Fig. 2 Survival analyses of patients according to different blood glucose levels

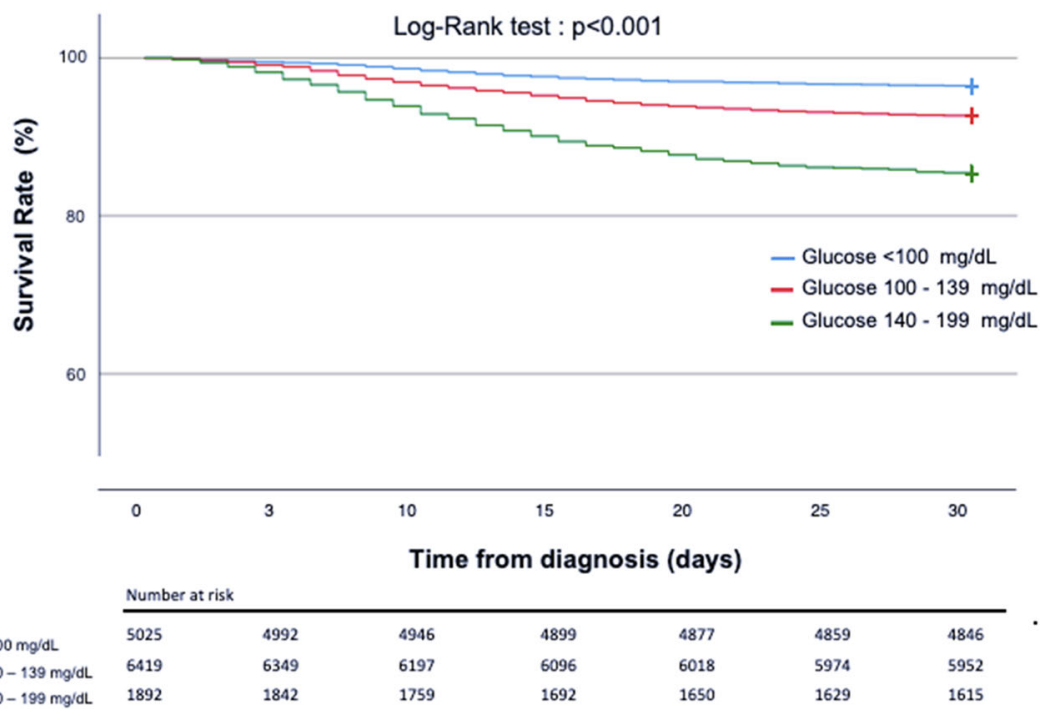

disease. Many studies reported that patients with prediabetes had increased risk of mortality and cardiovascular diseases [17]. It is also well known that hyperglycemia affects mortality in critical illnesses [18]. Also, previous studies have reported that hyperglycemia was associated with mortality in SARS and the Middle East respiratory syndrome (MERS) [19, 20]. There is a bidirectional relationship between hyperglycemia and SARS-CoV-2 infection. SARS CoV-2 uses the angiotensin-converting enzyme 2 (ACE-2) as the receptor for entry into the cells. Hyperglycemia classically impairs the immune system response by affecting neutrophilic chemotaxis and phagocytosis, but in SARS-CoV-2 infection, it may also increase the expression of the ACE- 2 receptors and cause a susceptibility $[21,22]$. Since the ACE-2 receptors are present in other organs too that regulate glucose hemostasis, it is also possible for SARS CoV-2 to cause hyperglycemia affecting these organs [21]. One of the causes of hyperglycemia in the course of COVID-19 disease may be stress hyperglycemia, which is frequently seen in various severe acute diseases and can be defined as transient elevation of blood glucose due to disease stress [23]. Although the underlying mechanisms are not fully elucidated, our results support the negative effect of hyperglycemia on the prognosis of COVID-19 disease.

It has been also shown that diabetes is an important risk factor for hospitalization in COVID-19 disease [24], but the effect of hyperglycemia for hospitalization of non-diabetic patients is unknown. Unlike other studies, the present study is the first one using random glycemia levels at the time of COVID-19 diagnosis to search for the effect of hyperglycemia levels on the prognosis of COVID-19 disease. This method eliminates the increase in glucose levels due to inflammation that may occur during the course of COVID19 disease or hyperglycemia that may develop secondary to drug use such as steroid therapy. Also, the use of glucose values at the time of diagnosis gave the opportunity to demonstrate the effect of hyperglycemia on hospitalization rates for the first time. Despite the striking effects of hyperglycemia on the clinical severity of COVID-19 disease, no effect was found on the hospitalization rates compared to normoglycemia levels. The possible reason for this result may be related to the hospitalization policy of the Ministry of Health, at the beginning of the pandemics. Patients, especially those with chronic diseases were hospitalized regardless of the symptom severity according to this policy.

There may be several limitations of the current study. First of all, the cross-sectional nature of the study may preclude the cause-effect relationship between clinical and laboratory parameters and outcomes. Also, there may be residual or unmeasured confounding factors. Second, although strict criteria have been used to identify nondiabetic patients, there is also the possibility of undiagnosed patients with diabetes in the groups. To eliminate the risk of misclassification of patients with diabetes mellitus into the study, we performed a targeted database search to identify any anti-hyperglycemic prescription in 12 months past. Additional to this limitation, we were not able to identify in the database whether glucose measurement was performed at a fasting state or random. Therefore, the present sample does not successfully represent the population with prediabetes. On the other hand, this may also be meaningful within the real-world conditions as most COVID-19 patients undergo blood sampling at any time of the day, though services may differ in other countries. Third, as the data obtained from the electronic data recording system of the Ministry of Health, some missing data could have a potential impact on the results. However, we believe that 
large patient population and the strict inclusion and exclusion criteria are the important strength of the present study.

In conclusion, this study demonstrated that glycemia levels especially in the range of $140-199 \mathrm{mg} / \mathrm{dL}$ at the time of COVID-19 diagnosis significantly increased the rates of ICU admission and/or a need for mechanical ventilation and mortality in non-diabetic patients. However, hyperglycemia was not found to have an impact on hospitalization rates. In the light of these findings, clinicians should be more careful, especially in the treatment of non-diabetic COVID-19 patients who had hyperglycemia at the time of diagnosis.

Acknowledgements We acknowledge all health care professionals with gratitude and respect who have devoted their lives to combating COVID-19 and have provided these data.

\section{Compliance with ethical standards}

Conflict of interest The authors declare no competing interests.

Ethics approval This study was approved by the COVID-19 Investigation Review Board (IRB) under the General Directorate of Health Services Bioethics Committee designated by the Ministry of Health. (IRB no: 95741342-020/27112019)

Publisher's note Springer Nature remains neutral with regard to jurisdictional claims in published maps and institutional affiliations.

\section{References}

1. WHO Coronavirus Disease (COVID-19) Dashboard. Available at "https://covid19.who.int/." Accessed on April 4, 2021.

2. Worldometer COVID-19 Coronavirus Pandemic. Available at "https://www.worldometers.info/coronavirus/." Accessed on April 4, 2021.

3. L. Roncon, M. Zuin, G. Rigatelli, G. Zuliani, Diabetic patients with COVID-19 infection are at higher risk of ICU admission and poor short-term outcome. J. Clin. Virol. 127, 104354 (2020). https://doi.org/10.1016/j.jcv.2020.104354

4. G.P. Fadini, M.L. Morieri, E. Longato, A. Avogaro, Prevalence and impact of diabetes among people infected with SARS-CoV-2. J. Endocrinol. Invest 43, 867-869 (2020). https://doi.org/10.1007/ s40618-020-01236-2

5. B. Bode, V. Garrett, J. Messler et al. Glycemic characteristics and clinical outcomes of COVID-19 patients hospitalized in the United States. J. Diabetes Sci. Technol. 14, 813-821 (2020). https:// doi.org/10.1177/1932296820924469

6. S. Wang, P. Ma, S. Zhang et al. Fasting blood glucose at admission is an independent predictor for 28-day mortality in patients with COVID-19 without previous diagnosis of diabetes: a multi-centre retrospective study. Diabetologia 63, 2102-2111 (2020). https://doi.org/10.1007/s00125-020-05209-1

7. A. Coppelli, R. Giannarelli, M. Aragona et al. Hyperglycemia at hospital admission is associated with severity of the prognosis in patients hospitalized for COVID-19: the Pisa COVID-19 study. Dia Care 43, 2345-2348 (2020). https://doi.org/10.2337/dc201380

8. C. Sardu, N. D'Onofrio, M.L. Balestrieri et al. Hyperglycaemia on admission to hospital and COVID-19. Diabetologia 63, 2486-2487 (2020). https://doi.org/10.1007/s00125-020-05216-2
9. F.J. Carrasco-Sánchez, M.D. López-Carmona, F.J. MartínezMarcos et al. Admission hyperglycaemia as a predictor of mortality in patients hospitalized with COVID-19 regardless of diabetes status: data from the Spanish SEMI-COVID-19 Registry. Ann. Med. 53, 103-116 (2021). https://doi.org/10.1080/ 07853890.2020 .1836566

10. Sonmez A., Demirci İ., Haymana C., et al.: Clinical characteristics and outcomes of COVID-19 in patients with Type 2 diabetes in Turkey: a nationwide study (TurCoviDia). J Diabetes (2021). https://doi.org/10.1111/1753-0407.13171

11. I. Satman, İ. Demirci, C. Haymana et al. Unexpectedly lower mortality rates in COVID-19 patients with and without type 2 diabetes in Istanbul. Diabetes Res. Clin. Pract. 174, 108753 (2021). https://doi.org/10.1016/j.diabres.2021.108753

12. A.S. Levey, L.A. Stevens, C.H. Schmid et al. A new equation to estimate glomerular filtration rate. Ann. Intern. Med 150, 604-612 (2009). https://doi.org/10.7326/0003-4819-150-9-200905050-00 006

13. Y. Sun, X. Guan, L. Jia et al. Independent and combined effects of hypertension and diabetes on clinical outcomes in patients with COVID-19: A retrospective cohort study of Huoshen Mountain Hospital and Guanggu Fangcang Shelter Hospital. J. Clin. Hypertens. (Greenwich) 23, 218-231 (2021). https://doi.org/10. $1111 /$ jch. 14146

14. P. Giorgi Rossi, M. Marino, D. Formisano et al. Characteristics and outcomes of a cohort of COVID-19 patients in the Province of Reggio Emilia, Italy. PLoS ONE 15, e0238281 (2020). https://doi. org/10.1371/journal.pone.0238281

15. G.A. Silverii, M. Monami, A. Cernigliaro et al. Are diabetes and its medications risk factors for the development of COVID-19? Data from a population-based study in Sicily. Nutr. Metab. Cardiovasc. Dis. 31, 396-398 (2021). https://doi.org/10.1016/j. numecd.2020.09.028

16. Y. Zhang, H. Li, J. Zhang et al. The clinical characteristics and outcomes of patients with diabetes and secondary hyperglycaemia with coronavirus disease 2019: a single-centre, retrospective, observational study in Wuhan. Diabetes Obes. Metab. 22, 1443-1454 (2020). https://doi.org/10.1111/dom.14086

17. X. Cai, Y. Zhang, M. Li et al. Association between prediabetes and risk of all cause mortality and cardiovascular disease: updated meta-analysis. BMJ 15, 370 (2020). https://doi.org/10.1136/bmj. m2297

18. B.W. Whitcomb, E.K. Pradhan, A.G. Pittas et al. Impact of admission hyperglycemia on hospital mortality in various intensive care unit populations. Crit. Care Med 33, 2772-2777 (2005). https://doi.org/10.1097/01.ccm.0000189741.44071.25

19. J.K. Yang, Y. Feng, M.Y. Yuan et al. Plasma glucose levels and diabetes are independent predictors for mortality and morbidity in patients with SARS. Diabet. Med. 23, 623-628 (2006). https://doi. org/10.1111/j.1464-5491.2006.01861.x

20. K.H. Alanazi, G.R. Abedi, C.M. Midgley et al. Diabetes mellitus, hypertension, and death among 32 patients with MERS-CoV infection, Saudi Arabia. Emerg. Infect. Dis. 26, 166-168 (2020). https://doi.org/10.3201/eid2601.190952

21. Roca-Ho H., Riera M., Palau V., et al. Characterization of ACE and ACE2 expression within different organs of the NOD mouse. Int. J. Mol. Sci. (2017). https://doi.org/10.3390/ijms 18030563

22. S. Rao, A. Lau, H.-C. So, Exploring diseases/traits and blood proteins causally related to expression of ACE2, the putative receptor of SARS-CoV-2: a mendelian randomization analysis highlights tentative relevance of diabetes-related traits. Dia Care 43, 1416-1426 (2020). https://doi.org/10.2337/dc20-0643

23. K.M. Dungan, S.S. Braithwaite, J.C. Preiser, Stress hyperglycaemia. Lancet 373(9677), 1798-1807 (2009). https://doi.org/10. 1016/S0140-6736(09)60553-5. 23 
24. Ko J.Y., Danielson M.L., Town M., et al. Risk Factors for COVID-19-associated hospitalization: COVID-19-associated hospitalization surveillance network and behavioral risk factor surveillance system. Clin. Infect. Dis. (2020). https://doi.org/10. 1093/cid/ciaa1419

\section{Affiliations}

\section{Cem Haymana $\mathbb{1}^{1} \cdot$ Ibrahim Demirci $^{1} \cdot$ Ilker Tasci $^{2} \cdot$ Erman Cakal $^{3} \cdot$ Serpil Salman $^{4} \cdot$ Derun Ertugrul $^{5} \cdot$ Naim Ata $^{6}$. Ugur Unluturk ${ }^{7}$ - Selcuk Dagdelen ${ }^{7} \cdot$ Aysegul Atmaca $^{8}$ - Mustafa Sahin ${ }^{9}$ - Osman Celik ${ }^{10} \cdot$ Tevfik Demir $^{11}$. Rifat Emral $^{9} \cdot$ Ibrahim Sahin $^{12} \cdot$ Murat Caglayan $^{13} \cdot$ Ilhan Satman $^{14,15} \cdot$ Alper Sonmez $^{16}$}

1 Department of Endocrinology and Metabolism, University of Health Sciences Turkey, Gulhane Training and Research Hospital, Ankara, Turkey

2 Department of Internal Medicine, University of Health Sciences Turkey, Gulhane Faculty of Medicine and Gulhane Training and Research Hospital, Ankara, Turkey

3 Department of Endocrinology and Metabolism, University of Health Sciences Turkey, Faculty of Medicine, Diskapi Yildirim Beyazit Training and Research Hospital, Ankara, Turkey

4 Department of Endocrinology and Metabolism, Medica Clinic, Istanbul, Turkey

5 Department of Endocrinology and Metabolism, University of Health Sciences Turkey, Faculty of Medicine, Kecioren Training and Research Hospital, Ankara, Turkey

6 Department of Strategy Development, Republic of Turkey, Ministry of Health, Ankara, Turkey

7 Department of Endocrinology and Metabolism, Hacettepe University, Faculty of Medicine, Ankara, Turkey

8 Department of Endocrinology and Metabolism, Samsun 19 Mayis University, Faculty of Medicine, Samsun, Turkey
9 Department of Endocrinology and Metabolism, Ankara University, Faculty of Medicine, Ankara, Turkey

10 Public Hospitals General Directorate, Republic of Turkey, Ministry of Health, Ankara, Turkey

11 Department of Endocrinology and Metabolism, Dokuz Eylul University, Faculty of Medicine, Ankara, Turkey

12 Department of Endocrinology and Metabolism, Malatya Inonu University, Faculty of Medicine, Malatya, Turkey

13 Ankara Provincial Health Directorate, Ankara, Turkey

14 Department of Endocrinology and Metabolism, Istanbul University, Faculty of Medicine, Istanbul, Turkey

15 Turkish Institute of Public Health and Chronic Diseases, Istanbul, Turkey

16 Department of Endocrinology and Metabolism, University of Health Sciences Turkey, Gulhane Faculty of Medicine and Gulhane Training and Research Hospital, Ankara, Turkey 